\title{
Systematic Review to Compare Serious Game and Traditional Learning to Engage Children doClean and Healthy Lifestyle
}

\author{
Sri Wulan Purwaningrum*, Nia Saurina**, Anang Kukuh Adisusilo*** \\ *(Department of Civil Engineering, University of WijayaKusuma Surabaya, East Java, Indonesia \\ Email: sriwulanpurwaningrum@gmail.com) \\ ** (Department of Informatics Technology, University of WijayaKusuma Surabaya, East Java, Indonesia \\ Email:niasaurina@gmail.com) \\ *** (Department of Informatics Technology, University of WijayaKusuma Surabaya, East Java, Indonesia \\ Email:kuper65@gmail.com)
}

\begin{abstract}
Life style plays an important role in bio-psychological health. There is an interlock relationship between health problems and life style. In other words, life style is one of the most important influential factors on individual's health and illness. In Indonesia, regulated about lifestyle has been regulated by The Minister of National Development Planning (MNDP).

From MNDP's report we know that nowadays children not live clean and healthy lifestyle correctly. Our aim in this article is to compare traditional learning and serious game to engage children do clean and healthy lifestyle. Our serious game is concern to help children get visualization about hand washing habit; how important to consume vegetable and fruit; drink adequate quantities of water that are free from contaminants.

Our game was name "My Lifestyle" and bring on serious game concept. In an anonymous survey 33 students from the first year and 35 students from the second year of DukuhKupang Elementary School in Indonesia were involved. They were counterbalanced and randomly assigned to one of two conditions:a) Children at the experimental group who played My Lifestyle game first and then the traditional learning method; b) Children at the traditional learning group who listen explanation about healthy lifestyle first and then played My Lifestyle game.

The results show that there is a significant difference between the two groups in learning the concepts of addition and subtraction $(<0.05)$, and the experimental group has a higher mean score than the traditional learninggroup. Moreover, the results indicate that there a significant difference between the two groups in retention of the concepts of addition and subtraction $(<0.05)$, with the experimental group scoring higher than the traditional learninggroup.
\end{abstract}

Keywords-My lifestyle game, serious game, experimental group, traditional learninggroup, systematic review

\section{INTRODUCTION}

Life style plays an important role in biopsychological health [1]. There is an interlock relationship between health problems and life style. In other words, life style is one of the most important influential factors on individual's health and illness [2]. On the basis of statistical data, 53\% of deaths are related to the life style [3]. Healthy life style causes a balance in life if which a person chooses intentional standards options for himself [4]. In fact, healthy life style has been considered as a valuable source for decreasing health problems, promoting health, managing stressful events and improving the quality of life [1].

International call for the development of a food based dietary guidelines (FBDGs) to promote appropriate diets and healthy lifestyle started in the
1992 International Conference on Nutrition when 159 Head of states committed to a plan of action on nutrition. Dietary guidelines, which is defined as sets of advisory statements that give dietary advice for population to promote overall nutritional well-being and relate to all diet-related conditions, was firstly discussed on a joint Food and Agriculture Organization (FAO)/World Health Organization (WHO) expert consultation in 1995 [5]. The guidelines shall provide advice in qualitative and quantitative information for different age groups and lifestyles appropriate for individual countries. They commonly contain information on foods or behaviors that are encouraged and cautionary messages derived from thorough process of scientific evidence based reviews of demographic, epidemiological, nutritional and social transitions 
$[6,7]$ as well as specific health, behavior, culture and economic conditions within a country $[8,9]$. In the years, afterward, the need to develop or improve the guidelines has been continuously reiterated globally and regionally $[9,10]$. The end goal of adherence to FBDG is a good quality of life for the whole life cycle.

In Indonesia, FBDG has been regulated by The Minister of National Development Planning Agency (MNDPA). From MNDPA's report show the substantial problem of nutrition and high number of nutrition-related diseases are correlated with social and cultural factors such as individual and family awareness to practice clean and healthy life style, including nutritional awareness. The Indicator of clean and healthy life style or in Indonesia known as PolaHidupBersihdanSehat (PHBS) is hand washing habit; exclusive breastfeeding; utilization of Posyandu by family; use of contraception (family planning); physical activities; number of population above 10 years who smoke; number of population above 10 years who consume less vegetable and fruit; access to proper sanitation; drink adequate quantities of water that are free from contaminants; and delivery assistance by health personnel [11]. Posyandu is a place where people can get health care with minimum cost.

Though Posyandu was still the first choice for weighing under five ( 81 percent), there was only 56 percent of under-five weigh for four times or more, even, 1 of 5 (20,8 percent) under five had not been weigh for the last six months. The $\mathrm{D} / \mathrm{S}$ indicator (number of weighed children towards total number of children in the area) should be the main performance indicator to monitor achievements of family and community empowerment. Drink adequate quantities of water that are free from contaminants behavior is also very concerning and it is increasing at relatively young ages. Children are preferred drink beverage packing than water. Number of those habit in age 5-9 years increased from 1.2 percent in 2010 to 1,7 percent in 2014 . It was found that number of population age 15 years above who eating fast food in daily basis reached 28,2 percent. Level of household expenditures and eating behavior of the family member had correlation with malnutrition incidence or even overweight, whereas 16 percent of under-five with malnutrition and 33 percent of overweight under five [11]. On the other side, vegetable and fruit consumption was still low, which was 93 percent.
This condition was worsened by the fact that almost half of Indonesian population (48,2 percent) had less physical activity. Correct hand washing habit was only practiced by 23 percent families and 71 percent families had already lavatory to bathing, washing and defecation. In general, there was only 1 of the 3 (38,7 percent) people who practiced the 10 indicators of PHBS. The above behavior, in actual, had strong correlation with the level of education and knowledge of family members.

Childhood is characterized by its close link to games. The concept, process, and benefits of games have always been considered by researchers. According to Buytendijk, games exist because of childhood [12]. Games provide children with opportunities to be creative and increase their abstract thinking; they serve as basis for optimal development of physical, social, emotional, and cognitive aspects in children [13]. By playing games, children have the chance to create a world where they dominate and can thus overcome their anxieties [14]. Games enable children to practice the skills required for facing future challenges; they can be regarded as a part of the educational environment that enable adaptation with school environment and help children learn, develop their emotional and social abilities, and improve their problem solving and abstract thinking [15]. The current definition of "Serious Games" appears to follow the lead set by Sawyer \&Rejeski [16]. However, the oxymoron "Serious Games" was used with a similar meaning before the publication of this white paper. Therefore, we will first review the origins of this term and analyse how it evolved to designate "games that do not have entertainment, enjoyment or fun as their primary purpose" [17]. Serious games could for example be useful for education at schools. Children with diabetes might face the consequences of skipping a meal or eating food with too many carbohydrates in such a game [18].

From MNDP's report we know that nowadays children not live clean and healthy lifestyle correctly. Our aim in this article is to compare traditional learning and serious game to engage children do clean and healthy lifestyle. Our serious game is concern to help children get visualization about hand washing habit; how important to consume vegetable and fruit; drink adequate quantities of water that are free from contaminants. 


\section{RELATED WORK}

There is no one definition of serious gaming. Indeed, 'gaming' itself does not have a single definition. Prensky [19] defined gaming as having six structural elements: rules, goals and objectives; outcomes and feedback; conflict, competition, challenge or opposition; interaction and representation or story. However, not all of these elements are present in every game [20].

Gaming has important characteristics that enhance some cognitive elements such selective attention [21], which can play an important role to behavior change, as they could help people pay more attention to the main message. Another very important characteristic gaming offers is that it also makes the learning process fun [23], which in turn generate better engagement. Complementary, games also help increase motivation [24] and emotional engagement [22].

Research present to compare the effectiveness of game-based and traditional teaching in learning were done by Bahrami et.al [25], they used population of the research consisted of all the female students of Khorramabad Province. The participants were selected using cluster sampling and were randomly divided into an experimental and a control group (31 participants in each group). The participants in the experimental group were taught according to game-based teaching and the participants in the control group underwent traditional learning. The learning test and the retention test were conducted one week and three weeks after teaching each method. The results showed that the experimental group had higher scores in learning tests (except for the concept of correspondence) and retention tests (concepts of left and right, correspondence, equality, less than and greater than signs, and addition and subtraction) ( $\mathrm{p} \leq$ 0.05). It can thus be concluded that using educational games in teaching of first grade math concepts can be remarkably helpful and efficient.

David et al [26] present an initial study to determine the subject preferences for educational computer games for children, in which 150 education professionals participated. From the results of this first study, they were developed an iPhone game for transmitting knowledge as part of multiculturalism, solidarity and tolerance following established learning theories, several design principles, and the objectives and competences of the Spanish law for primary education. For learning outcomes, the results did not show significant differences between the two groups. However, 96\% of the children indicated that they would like to play with the iPhone game again, and $90 \%$ indicated that they preferred the experience with the iPhone game over the traditional one. From these results, they conclude that the children achieved similar knowledge improvements using both the autonomous game (iPhone game) and the custom, guided game (traditional game).

\section{METHODOLOGY}

\subsection{Description about the Game}

The subject of the game is concern to help children to get visualization about hand washing habit; how important to consume vegetable and fruit; drink adequate quantities of water that are free from contaminants. In our game children get visualization their activity in their daily life. Our game was name "My Lifestyle" and bring on serious game concept. In order to familiarize the children with the game and its different ways of interaction they first follow a tutorial. Scenario explains what task must the player do. My Lifestyle's scenario has the following structure:

1) Start play My Lifestyle game, the players click on button "Play", then game will show two character and there are boys or girls, as seen in Figure 1. Players could choose one of those characters and the selected character is show throughout the game. After player choose character, player need to choose three themes i.e. morning, daylightand noon. Players must start play game from "morning", because others environments are locked, which can be seen in Figure 2.
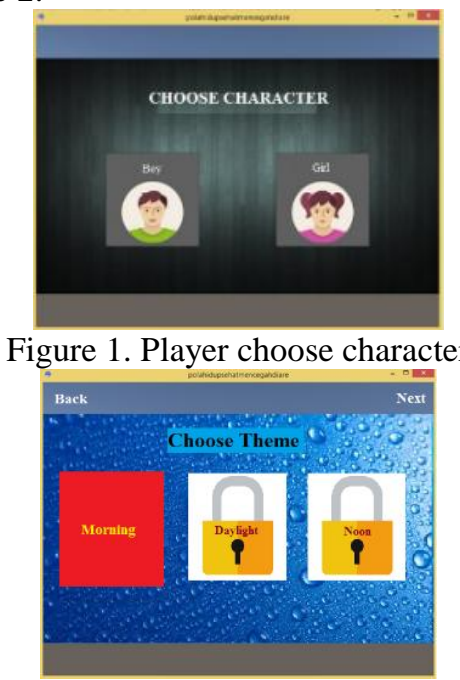

Figure 2. Player choose theme

2) Player do task hand washing habit, to complete this task, player need click washing hand icon 
before they pick up their food for breakfast. There is icon wash hand appear on the top left side to remain player, they need to wash their hand before choose food and drink, which can be seen in Figure 3. If the player click icon wash hand first before choose food, then player got "hand washing reward", but they click food or drink first then icon wash hand they won't have any reward. At the Morning and noon theme, game appear home environment and at the daylight theme game will appear school environment which is school canteen, as seen in Figure 4.

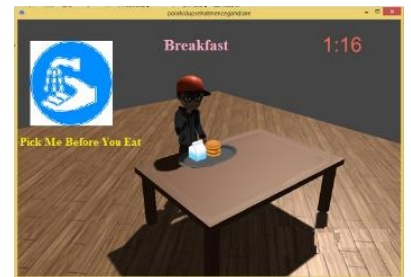

Figure 3. Home Environment, Morning theme

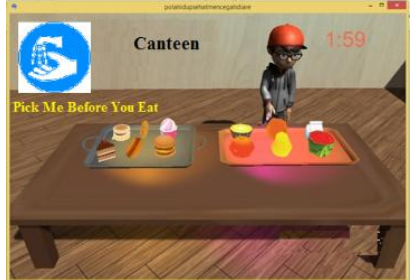

Figure 4. Canteen Environment, daylight theme

3) Player do task to consume vegetable and fruit, to complete this task, player need click vegetable or fruit when player choose any kind of food, as seen in Figure 5. If the player clicks icon vegetable or fruit once, then player got "vegetable and fruit reward", but if the player not to choose any kind vegetable or fruit then player did not get any reward.

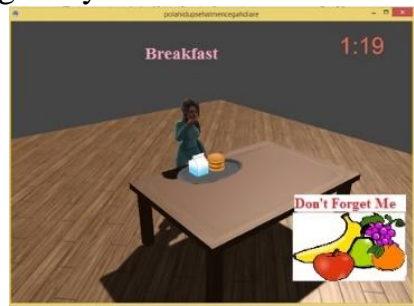

Figure 5. Game remain fruit and vegetable to player

4) The daily amount of water that a child needs depends on factors such as age, weight and gender. From Institute of Medicine of the National Academies [28] children in age 4 to 8 years old for boys and girls, need 5 cup / day. So, this game calculates at least 5-time player choose water icon so that player gets water reward, as send in Figure 6. Water icon appear in scene playing football (boy), riding a bicycle (girl); study at home; study at class; clean up the bedroom; clean up the living room.

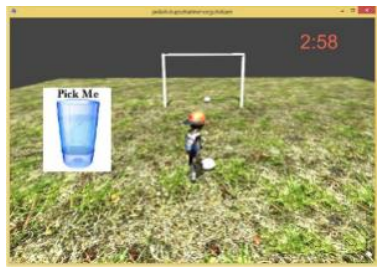

Figure 6. Game show glass of water icon, while he playing football

When player running the game, game show main menu and game asked the player, is he/she play game or exit game. When player "Exit", then game will be end. When player choose "Play". In the main menu there are sub process play background music and highlight selected option. After player choose "Play", player should choose character, is he/she want to play as "Boy" or "Girl". Game show character game as chosen player. When game begin, the first theme is morning theme, because daylight theme and noon theme are locked. At the morning theme, there are three scenes which is "take a bath", "Breakfast Time" and "clean up the bedroom". In the scene "Take a bath", player could click soap and move it into character's body, and game will show bubble. Player could click scoop to take water on bath up and game show character's game rinse soap bubbles. After that player can click tooth brush and tooth paste to brush their teeth. These scene has the same scenario in the scene "Take a Bath" in noon theme. In the scene "Breakfast Time", player can choose any kind of food and hand wash icon appear in 5 second. When player click hand wash icon, then player got hand wash as reward. After 5 second, game show fruit and vegetable icon, when player choose this icon, then player get fruit and vegetable icon as reward. This scene has the same scenario in "Dinner Time" at the noon theme. At the scene "Lunch Time", has the similar scenario with "Breakfast Time" and "Dinner Time", it is just show glass of water icon in scene "Lunch Time". At the scene "Clean up the Bedroom" and "Clean up the living room" has the same scenario, player can click item to clean up. This item are toys, books, stationary. At the scene "Playing Outdoor", there are two games. When player choose boy then game show playing football, and when player choose girl then game show riding a bicycle. While player in this scene, player should click glass of water to get reward. Every game in each scene has timer 2 minutes. Whole stories in My Lifestyle game can be seen in Figure 7. 


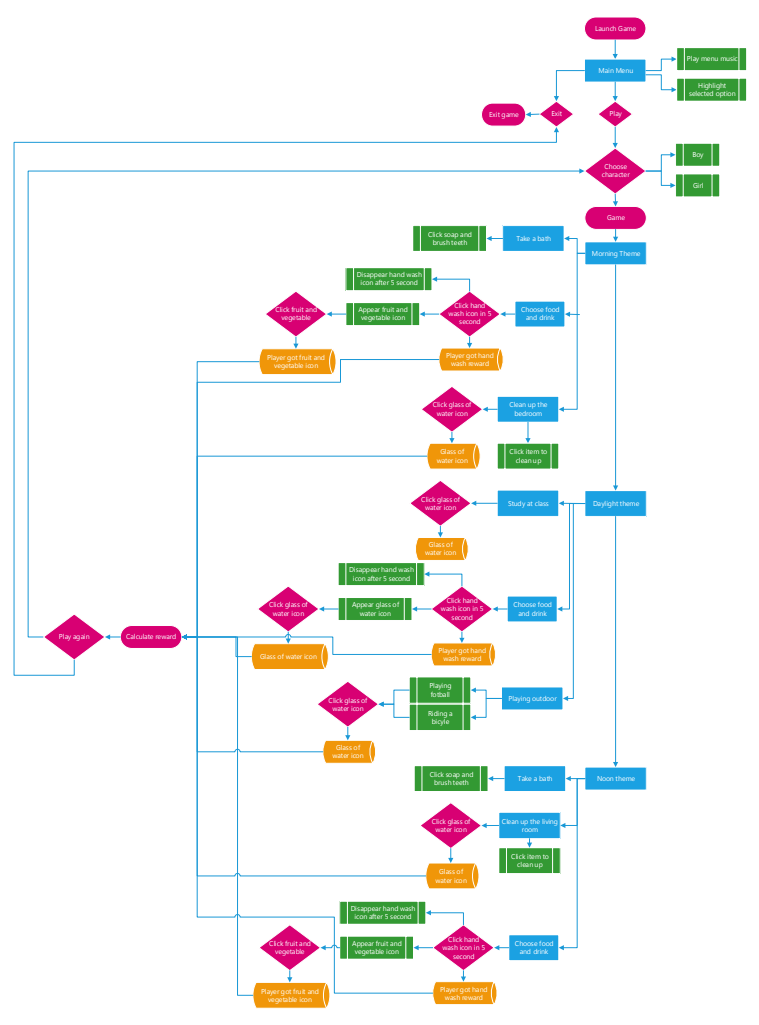

Figure 7. Flowchart MyLifestyle Game

\subsection{Participant}

In an anonymous survey 33 students from the first year and 35 students from the second year of Dukuh Kupang Elementary School in Surabaya City, Indonesia were involved. We divided children into two groups and there are the experimental group and the traditional learninggroup. The experimental group started My Lifestyle game to engage clean and healthy lifestyle and the control group underwent the traditional learningmethod.

At the traditional learninggroup, research with helped the teacher, bring the teaching materials included props health such as soap toy, small towel, fruit and vegetable toys, image for human skeleton for kids, glass and water. At the experimental group research with helped the teacher start play My Lifestyle games used for teaching clean and healthy lifestyle concepts included washing hand, drink enough water, eat fruit and vegetable. It must be noted that the research environment was equal for both groups. The tests were conducted simultaneously and with the same content for both groups. The tests were designed by the teacher and were based on the concepts of Kurikulum Nasional book (2013-2017). The face and content validity of the tests were confirmed by experienced teachers. The data was analyzed using descriptive statistics (mean, standard deviation, etc.), independent t-test (between-group comparisons), and effect size (ES).
The statistical operations were done in SPSS 15 and Effect Size Calculator at the 0.05 significance level.

\subsection{Measurement}

Two questionnaires were used for the validation. The first one was dedicated to traditional learninggroup was composed of 19 questions. The first 14 questions were designed to evaluate the children's degree of knowledge after they listen explanation about healthy lifestyle, we name as Question Traditional Group (QTG). They were multiple-choice questions with 1 or 2 possible answers scoring as like or dislike. As an example, one of these questions was: How many cups that you need to consume in every day a) 4 cup / day, b) 5 cup / day, c) 6 cup / day. Four of the 14 questions were related to hand washing habit, six of the 14 questions were related to how important to consume vegetable and fruit, and four of the 14 questions were related to quantities of water that are free from contaminants.

The last 5 questions of the first questionnaire were related to the participant's satisfaction with traditional learningmethod. The first four of these last 5 questions were multiple-choice questions with 3 to 5 possible answers. These questions were related to: 1) the experienced amusement; 2) perceived learning; 3) easy to understand; 4) if they would like to listen explanation about healthy lifestyle to know another healthy lifestyle. These four questions were used as the satisfaction variable. The last question was: Score the game from 1 to 10 , where 1 was the lowest value and 10 was the highest value.

The second questionnaire was dedicated to experimental group, we name as Question Experimental Group (QEG) was focused on knowing the children's preferences and their opinion about My Lifestyle game. It had 12 questions. The first 11 were multiple-choice questions with 3 to 5 possible answers. As an example, the first question of this second questionnaire was: How often do you play with consoles (e.g. Wii) or computer games?, a) every day; b) nearly every day; c) some days; d) hardly ever; e) never. Another of these questions was: Has it been easy to play with My Lifestyle game? 1) strongly disagree; 2) disagree; 3) neither agree nor disagree; 4) agree; 5) strongly agree. Questions 6 and 8 had three subscales with 4 possible options each. For example, question 6 was: Mark what you liked the most about themes game. The three subscales corresponded to morning theme, noon theme, evening theme, and night theme. Question 12, the last question, was used to determine which game the children preferred, the My Lifestyle game or the traditional learning group. 


\subsection{Procedure}

The children voluntarily participated in this study with the consent of their teacher. They were counterbalanced and randomly assigned to one of two conditions:

a) Children at the experimental group who played My Lifestyle game first and then the traditional learningmethod.

b) Children at the traditional learninggroup who listen explanation about healthy lifestyle first and then played My Lifestyle game.

After playing serious game, the children in the first group filled out the QEG. Then they listen explanation about healthy lifestyle and filled out the QTG. After playing the traditional game, the children in the second group filled out the QTG, then they played serious game and filled out the QEG.

The questionnaires were filled out in the same room where the activities took place and were monitored by the one of team of research and one teacher. This person interfered as little as possible during the activity. He gave the game on the laptop to the children and they started playing. It is important to note that, with the laptop, it was not possible to hear a message again once it had already been heard. The person in charge also took notes of the players using an observation sheet. The observation sheet for the traditional game was composed of 7 sections related to initial behavior, initial motivation, understanding healthy lifestyle, engagement and fun with material, cooperation between the users, and perceived understanding of the concepts explained healthy lifestyle. There was also an additional section where they could add other perceptions that did not pertain to the sections described. Every section had a scoring scale from 1 to 10 in which the person observing the players could score the performance of the players in each one of the aspects mentioned. There was also a free space in each section in which the observer could take notes about the players. The observation sheet for the game contained the same sections as the traditional observation sheet plus one more section that was related to the interaction with the device.

To compare the game, we designed several traditional games so that the children received the same information as in My lifestyle game. Moreover, an adult guided the children during the game and explained everything to them. If they did not understand something, the adult repeated the message and made sure that the information always arrived to the students. Table 1 shows a comparison between the Traditional Method and My Lifestyle Game.
Table 1. Comparison Between the Traditional Method and My Lifestyle Game

\begin{tabular}{|c|c|c|}
\hline Game & Traditional Method & My Lifestyle Game \\
\hline Introduction & $\begin{array}{l}\text { The teachershows a } \\
\text { printed human skeleton } \\
\text { with elements to find. } \\
\text { Theteacherfocuses on } \\
\text { human body and gives } \\
\text { some details about the } \\
\text { important of clean and } \\
\text { healthy lifestyle that } \\
\text { they have to implement } \\
\text { in their daily life. }\end{array}$ & $\begin{array}{l}\text { An animation with the } \\
\text { elements to find appears } \\
\text { on the laptop screen. } \\
\text { The guide character } \\
\text { gives the same } \\
\text { information as in the } \\
\text { traditional game. }\end{array}$ \\
\hline $\begin{array}{l}\text { Hand } \\
\text { washing } \\
\text { habit }\end{array}$ & $\begin{array}{l}\text { The teachershows soap } \\
\text { toy and move it on } \\
\text { palm and back of the } \\
\text { hand. Soap toy moving } \\
\text { up and down, also put } \\
\text { soap toy between the } \\
\text { fingers. After show } \\
\text { hand washing } \\
\text { examples, the } \\
\text { instructor shows drying } \\
\text { hands with towel or } \\
\text { tissue. }\end{array}$ & $\begin{array}{l}\text { Children as player pick } \\
\text { up any kind of food, but } \\
\text { when they do not } \\
\text { choose hand washing } \\
\text { icon, they won't receive } \\
\text { hand washing icon as } \\
\text { reward at the end of the } \\
\text { game. }\end{array}$ \\
\hline $\begin{array}{l}\text { How } \\
\text { important to } \\
\text { consume } \\
\text { vegetable } \\
\text { and fruit }\end{array}$ & $\begin{array}{l}\text { The teachershows } \\
\text { vegetable and fruit toy } \\
\text { and explained the } \\
\text { benefit of each toy } \\
\text { when children } \\
\text { consume it. }\end{array}$ & $\begin{array}{l}\text { Children as player pick } \\
\text { up any kind of food, but } \\
\text { when they do not } \\
\text { vegetable or fruit, they } \\
\text { won't receive vegetable } \\
\text { and fruit icon as reward } \\
\text { at the end of the game. }\end{array}$ \\
\hline $\begin{array}{l}\text { Drink } \\
\text { adequate } \\
\text { quantities of } \\
\text { water that } \\
\text { are free from } \\
\text { contaminants }\end{array}$ & $\begin{array}{l}\text { The instructoruses a } \\
\text { glass of water and } \\
\text { printed human } \\
\text { skeleton. In printed } \\
\text { human skeleton, the } \\
\text { instructor using black } \\
\text { folding paper to } \\
\text { pretend as bacteria in } \\
\text { stomached, printed } \\
\text { human body. The } \\
\text { instructor explained } \\
\text { when children } \\
\text { consume glass of water } \\
5 \text { cup / day, the } \\
\text { bacteria will be gone } \\
\text { through the pee or } \\
\text { defecate. }\end{array}$ & $\begin{array}{l}\text { Children as player pick } \\
\text { up any kind of food, } \\
\text { fruit or vegetable, but } \\
\text { when they do not } \\
\text { choose glass of water } \\
\text { icon as much as five } \\
\text { time, then player won't } \\
\text { receive glass of water as } \\
\text { reward at the end of the } \\
\text { game. }\end{array}$ \\
\hline
\end{tabular}

\section{RESULT AND DISCUSSION}

The descriptive statistics and the results of independent t-test are presented in Table 1. The results show that there is a significant difference between the two groups in learning the concept of left and right $(<0.05)$. The comparison of test scores shows that the experimental group obtained higher scores in this concept. There is also a significant difference between the two groups in retention of the concept of left and right $(<0.05)$, with the experimental group scoring higher than the traditionallearninggroup. Based on the findings, there is no significant difference between the two groups in learning the concept of one-to-one correspondence, but a significant difference was observed in the retention of this concept. Comparing the mean retention scores shows that the 
experimental group obtained a higher score than the traditional learninggroup and the value of Cohen'sis greater than 0.8 , suggesting that the effect size is high [29]. It was also revealed that there is a significant difference between the two groups in learning the concepts of equality and inequality ( < 0.05). Comparison of the means indicates the higher score of the experimental group. A significant difference was observed between the two groups in retention of the concepts of equality and inequality, with the experimental group scoring higher in the retention test. The results show that there is a significant difference between the two groups in learning the concepts of addition and subtraction ( $<0.05$ ), and the experimental group has a higher mean score than the traditional learninggroup. Moreover, the results indicate that there a significant difference between the two groups in retention of the concepts of addition and subtraction $(<0.05)$, with the experimental group scoring higher than the traditional learninggroup.

Table 2 - Comparison of the learning and retention scores of the experimental group and the traditional learninggroup $(\mathrm{X} \pm \mathrm{SD})$

\begin{tabular}{|l|c|c|c|c|}
\hline \multicolumn{1}{|c|}{ Variables } & \multicolumn{3}{|c|}{ Statistics } \\
\cline { 2 - 5 } & $\begin{array}{c}\text { Traditional } \\
\text { Teaching } \\
\text { Group } \\
\text { (N=31) }\end{array}$ & $\begin{array}{c}\text { Experimental } \\
\text { Group } \\
(\mathrm{N}=31)\end{array}$ & $\mathrm{T}$ & $\begin{array}{c}\text { P- } \\
\text { value }\end{array}$ \\
\hline $\begin{array}{l}\text { Direction } \\
\text { (Learning) }\end{array}$ & $17.5 \pm 1.1$ & $18.5 \pm 0.6$ & 4.2 & 0.000 \\
\hline $\begin{array}{l}\text { Direction } \\
\text { (Retention) }\end{array}$ & $16.7 \pm 1.6$ & $17.9 \pm 1.0$ & 3.3 & 0.001 \\
\hline $\begin{array}{l}\text { One to one } \\
\text { Correspondence } \\
\text { (Learning) }\end{array}$ & $18.4 \pm 1.4$ & $19.5 \pm 0.7$ & 1.6 & 0.114 \\
\hline $\begin{array}{l}\text { One to one } \\
\text { Correspondence } \\
\text { (Retention) }\end{array}$ & $19.3 \pm 1.0$ & $19.7 \pm 0.6$ & 0.4 & 0.000 \\
\hline $\begin{array}{l}\text { Equality and } \\
\text { Inequality } \\
\text { (Learning) }\end{array}$ & $18.6 \pm 1.4$ & $19.3 \pm 0.9$ & 2.2 & 0.027 \\
\hline $\begin{array}{l}\text { Equality and } \\
\text { Inequality } \\
\text { (Retention) }\end{array}$ & $18.4 \pm 2.0$ & $19.3 \pm 0.9$ & 2.2 & 0.029 \\
\hline $\begin{array}{l}\text { Addition and } \\
\text { Subtraction } \\
\text { (Learning) }\end{array}$ & $18.9 \pm 1.3$ & $19.6 \pm 0.7$ & 2.9 & 0.005 \\
\hline $\begin{array}{l}\text { Addition and } \\
\text { Subtraction } \\
\text { (Retention) }\end{array}$ & $18.5 \pm 1.8$ & $19.5 \pm 0.8$ & 2.4 & 0.016 \\
\hline
\end{tabular}

\section{CONCLUSION}

The results of the present research showed that, in comparison to traditional learning, game-based teachingimproves learning and retention of such healthy lifestyle concepts as light and left, equality and inequality, and addition andsubtraction. In terms of the concept of one-to-one correspondence, a significant difference was observed only in theretention scores of the two groups. The theoretical basis and empirical evidence that support the advantage of game-basedlearning are as follows:

Game-based learning (experimental group) can be considered as an active learning method. Active learning is a method of instruction inwhich learners actively participate in the learning process. In the present research, the students participated inthe designated games for each component of healthy lifestyle and then started to work on the exercises of the course book. Therefore, it can be argued that serious game turn learning into a direct experience and create conditions where the learner isconstantly required to make decisions. Games enable students to witness the outcome of their actions. Whileplaying, children can use the data from their errors during the game to create a pattern that will allow them to solvenext problems more easily. The feedback children receive during the game quickly and objectively informs them oftheir performance.

These findings are encouraging and suggest that My Lifestyle Game based on serious game are wellaccepted and appreciated by students. The contribution of this paper is that it described a concrete case study on the creation and evaluation of a serious game designed according to instructional game design principles. In more detail, the game included interaction and feedback elements, a background story, clear rules, objectives and outcomes, combined with educational aspects. As it became apparent through the evaluation process, such a game can be easily integrated into the classroom to support the teaching of formal curricular material. Moreover, it can be used for distance learning, if certain extensions are considered. Finally, this paper demonstrated that it is possible to create a functional prototype of an online game that can be adapted according to the educator's specific needs. In conclusion, it is hoped that this study adds to the existing research on instructional games and that the presented game will eventually become an effective educational tool.

\section{Acknowledgements}

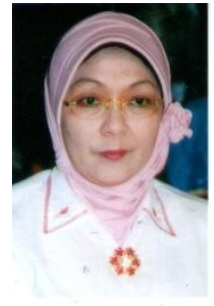

Sri Wulan Purwaningrum Born on December 12, 1954, which is often called by Wulan. S1 Wulan completed in 1981 in Isntitut Technology Surabaya majoring in Engineering Physics. In 2000 Wulan has completed a study S2 at Airlangga University Department of Public Health. Starting his career as a lecturer in 1987 at the University of Wijaya Kusuma Surabaya. 


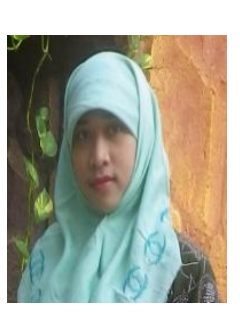

Nia Saurina Born on June 9, 1984, the second child of the couple Mochamad Gufron and Martina Endah Setyaningsih. Nia finished D4 studies in Electronic Engineering Polytechnic Institute of Surabaya in 2006 , followed by S2 studies at the Institute of Technology Surabaya at the Department of Information in 2009. Nia focus in software engineering with some of the research that has been done and published in IJETTCS (Thomson Indexing, 2016)

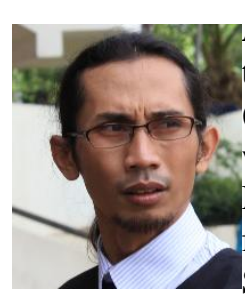

Anang Kukuh Adisusilo received the bachelor's (S.T) and master (M.T) in Electrical Engineering with focus riset studies on Multimedia Technology and Game from Institut Technology of Sepuluh November Surabaya (ITSSurabaya), Indonesia. During 20092016, he focuses in Multimedia Sistem and Game Technology with some of the research that has been done as published in the international journal JATIT (Scopus Indexing, 2015)

\section{REFERENCES}

[1] Rafifar S, Ahmadzadasl M. Esmaily M, et al., Health promotion. Tehran (Mehrravash Press, Persian, 2005).

[2] Tashiro J., "Exploring health promoting lifestyle behaviors of Japanese college women: perceptions, practices, and issues", Health Care for Women International Conference, pp 59-70, 2002.

[3] Baroogh NS., Nuktehdan H., Kazemnejad A., et al, "Comparing the lifestyles of first and final term female BS nursing students", Journal of Faculty of Nursing \& Midwifery Vol. 2 pp 55-62, Persian, 2003.

[4] Li G, Zhang P, Wang J, et al., The long-term effect of lifestyle interventions to prevent diabetes in the China Da Qing Diabetes Prevention Study: a 20-year follow-up study (The Lancet Press, China, 2008).

[5] WHO \& FAO, Preparation and use of foodbased dietary guidelines: Report of a joint FAO/WHO consultation(WHO Technical Report Series 880, WHO, 1998).
[6] Schneeman BO, Evolution of dietary guidelines (J Am Diet Association, 2003).

[7] Woolf SH., Weighing the evidence to formulate dietary guidelines (J Am Coll Nutr, 2006).

[8] Albert J. Global patterns and country experiences with the formulation and implementation of food-based dietary guidelines. Ann Nutr Metab. 2007;51(S2):2-7.

[9] WHO Regional Office for Southeast Asia, Development of food-based dietary guidelines for the Asian region. Final report of the recommendations of the Asian Nutrition Forum/WHO Symposium on Diet Related Chronic Diseases in Asia, WHO, 1998.

[10] WHO Regional Office for the Eastern Mediterranean \& FAO Regional Office for the Near East, FAO/WHO technical consultation on national food-based dietary guidelines, WHO, 2006.

[11] National Development Planning Agency, Report on the Achievement of the Millennium Development Goals, Indonesia, 2015.

[12] Ginsburg, K. R., "The importance of play in promoting healthy child development and maintaining strong parent- child bonds", Pediatrics Journal, Vol. 1, pp 182-191. doi:10.1542/ peds.2006-2697, 2007.

[13] Glantz SA, No association of smoke-free ordinances with profits from bingo and charitable games in Massachusetts. Ecco Press, 2003.

[14] Aber, J. L., Jones, S., \& Cohen, J. The impact of poverty on the mental health and development of very young children. In C. H. Zeanah Jr. (Ed.), Handbook of infant mental health (2nd ed., pp. 113-128). New York, NY: Guilford Press, 2000.

[15] Hewit, S, Can Play-Based Curriculum Survive the Standards Storm? A Teacher Educator' s Perspective. Play, Policy, \& Practice Connection, Ross Piper, 2001.

[16] Sawyer, B., \& Rejeski, D, "Serious Games: Improving Public Policy Through Game-based Learning and Simulation", European Scientific Journal, 2002.

[17] Michael, D., \& Chen, S, Serious Games: Games That Educate, Train, and Inform, Course Technology PTR, 2005.

[18] Thompson, D., T. Baranowski, and R. Buday, "Conceptual Model for the Design of a Serious Video Game Promoting Self-Management among Youth with Type 1 Diabetes", Journal of Diabetes Science and Technology, Vol. 4(3), pp. 744-749, 2010.

[19] Prensky, M., "Digital natives, digital immigrants part 1", On the horizon, 2001.

[20] Marsh, T, "Serious games continuum: Between games for purpose and experiential 
environments for purpose", Entertainment Computing Journal, Vol. 2, pp. 61-68, 2011.

[21] S. Green, D. Bavelier, Action video games modifies visual selective attention. Nature Press, 2003

[22] S. Hsu, F. Lee, M. Wu, "Designing Action games for appealing to buyers. Cyberpshychology Behavior Journal, Vol. 8 pp 85-91, 2005.

[23] Malone, T.W., What Makes Things Fun to Learn?: Heuristics for Designing Instructional Computer Games. In Proc. SIGSMALL, ACM Press, NY, USA, 1980.

[24] R. Ryan, C. Rigby, A. Przbylski. "The motivational pull of videogames: a selfdetermination theory approach. Motivation and Emotion Ltd, 2006

[25] Farid Bahrami, Zahra Rahimi Chegini, Asghar kianzadeh, et al, "A comparison of the effectiveness of game-based and traditional teaching on learning and retention of first grade math concepts", European Journal of Experimental Biology, Vol. 2 pp 99-106, 2012

[26] David Furióa, Santiago González-Gancedoa, M.-Carmen Juana, et al, "Evaluation of learning outcomes using an educational iPhone game vs. traditional game", International Journal of Gaming and Computer-Mediated Simulations. Vol. 1, pp 1-10, 2013

[27] Harry N. Boone, Jr., Deborah A. Boone. "Analyzing Likert Data", Journal of extension, April 2012 Volume 50 Number 2, 2012

[28] National Academy of Science, Dietary Reference Intake, Washington D.C., 2006.

[29] Cohen,J. Revised Edition, Englewood Cliffs, New jersey: Erlbaum. 1997. 